\title{
Factors Affecting Teacher Adoption of Mobile Learning in Teachers' Educational Technology Ability Training: A Case Study in a Pharmaceutical University
}

\author{
Yang Wei-jie ${ }^{1, a}$, Du Fang-fang ${ }^{2, b}$ \\ ${ }^{1}$ School of Information, Guangdong Teachers College of Foreign Language and Arts, Guangzhou \\ 510640, China; \\ ${ }^{2}$ College of Medical Information Engineering, Guangdong Pharmaceutical University, Guangzhou \\ 510640, China; \\ ayangwj@gtcfla.net, bdufangfang110@126.com
}

Keywords: educational technology ability, training, mobile learning, Lanmoyun class, adoption.

\begin{abstract}
In the "Internet plus education" era, university teachers' educational technology training courses in China need to be updated and improved. Under the guidance of "National University Teachers' Educational Technology Ability Guidance", and combined with the actual demand, the authors developed a new curriculum content system for the training course in a pharmaceutical university in Guangdong province in China, and implemented the training courses based on Lanmoyun class platform. Then carried out an investigation research(N=153,Cronbach's Alpha= 0.961) to explore the factors affecting teacher adoption of mobile learning in the teachers' educational technology ability training, an extended version of model was developed based on the Technology Acceptance Model (TAM), which was estimated using Structural Equation Modeling (SEM).
\end{abstract}

\section{Introduction}

In China, with the impact of a series of new technologies, such as mobile learning, cloud computing, big data, MOOCs, learning and analysis technology, virtual reality technology widely used in schools, mobile learning is becoming more and more popular, and the construction of Educational informationization in China followed into the "Internet plus education" era. The National Policies included "The National Education Plan in 13th Five-Year" [1] and "The national medium and long term program for education reform and development (2010-2020) " emphasized that Information technology has a revolutionary influence on the development of education, and must paid great attention to it, so as to deepen the integration of information technology with education, to establish a new information teaching environment for teachers and students, and optimize the educational model and promote the reform of education[2]. In the field of higher education, the innovation and implementation of educational technology brings not only new teaching models but also profound changes including the supplement of learning resources, educational concept and devices, so the teachers need to study new educational technology to keep up with these change.

Teachers' Educational Technology Ability Training is a kind of training aimed at improving the ability of teaching technology for teachers in colleges and universities, which is mainly carried out by the modern educational technology center of the school. In this study, the authors developed a teachers' educational technology ability course in a pharmaceutical university in Guangdong province based on Lanmoyun class platform which supported mobile learning, and carry out the training. The authors carried out an investigation research to explore the factors affecting the adoption of mobile learning in the educational technology ability training so to improve the design of training platform and the arrangement of curriculum contents, and improve teaching quality. 


\section{Education technical ability training course based on mobile teaching platform}

\subsection{The construction guide of the training course}

The design of the training course was mainly based on the "National Educational Technology Guides for Teachers in Higher Education(Trial Edition)" issued by the national education technology cooperation committee in 2010[3].The guide included five parts: Consciousness and responsibility, Knowledge and skills, Design and Implementation, Teaching evaluation, Scientific research and development, it totally have 17 two level indicators and 54 three level indicators [4].

\subsection{The objective of the training course}

The objective of the course included three aspects: (1)strengthen the understanding of University Teachers' teaching reform and innovative talents training supported by information technology tools, and enhance teachers' awareness of effective application of educational technology;(2)improve the ability of teachers to apply technical tools in teaching effectively and promote the teaching quality;(3)improve the ability of university teachers to use technology to carry out teaching and scientific research.

\subsection{The content system of the training course}

The content system of the course included five modules: Theoretical learning, Teaching preparation, Teaching implementation, Teaching evaluation, Teaching and scientific research work. (1)The Theoretical learning module was mainly composed of Educational Technology basic theory, Models and methods of Instructional Design, Digitalized teaching, Information technology tools, and the application of new technology.(2)The Teaching preparation module was mainly composed of How to make Multimedia courseware, How to make micro lesson, New technologies applied in pharmaceutical teaching.(3)The Teaching implementation module was mainly composed of classroom teaching based on Information technology, Design and implementation of Network Courses and Blended Learning Courses.(4)The Teaching evaluation module is mainly composed of Evaluation of student electronic portfolios and Evaluation of teacher professional development portfolios.(5) The Teaching and scientific research work module was mainly composed of literature searching and patent novelty searching tools, SPSS, etc.

\subsection{The curriculum platform and implementation of the course}

Lanmoyun class platform is a free teaching tools developed by Mosoink Information Technology Co. Ltd.in Beijing. It is based on Mobile terminals that can feedback and interaction in time, and support PC, mobile, tablet and other teaching equipment. With the teacher terminal, teachers can create courses, upload resources, create activities includes publish assignment, vote, brainstorm, discussion and online-test. With the student terminal, students can join the course, sign in and finishes the activities include upload the assignment, vote, discussion and online-test [5]. The author build the training course in the platform and create the invitation code, then invited the students join the course with their mobile devices. The training course use a blended learning method base on the Flipped Classroom Model as shown in Fig 1. Before the class, the Teachers first add relevant learning resources and Micro lessons videos on the platform for the students. Students learn resources on the platform by mobile devices. If there were any problems, they could consult or find supports after class. In the classroom, teachers give concise presentation on related topics, organize students to the discuss or collaborate, then answer questions and help the student's individually. 


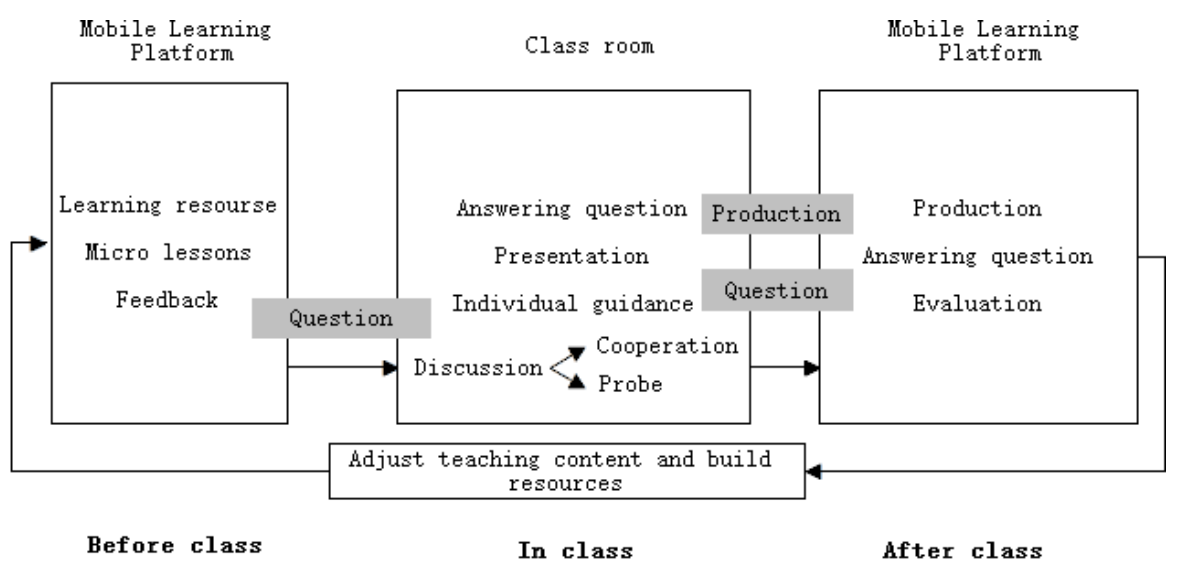

Fig.1 The blended learning method for training base on the Flipped Classroom Model

\section{The Technology Acceptance Model}

The Technology Acceptance Model (TAM) is a model to study users' acceptance of information systems using rational behavior theory (Davis, 1989) [6], the original purpose of the TAM is to explain the decisive factors that whey computer are widely accepted. There were two main determinants putted forward in the TAM, Perceived usefulness and perceived ease of use. Perceived usefulness reflecting to what extent someone believe a specific system can improve the performance of his work, and perceived ease of use, reflecting to what extent someone believe a specific system ease of use. The TAM believed that the use of the system was determined by the behavioral intention, and behavioral intentions were determined by the attitude toward using and the usefulness of perception, attitude toward using were determined by the perceived usefulness and perceived ease of use, perceived usefulness is determined by perceived ease of use and external variables, perceived ease of use was determined by external variables.The basic model of TAM is shown as Fig 2 [7].

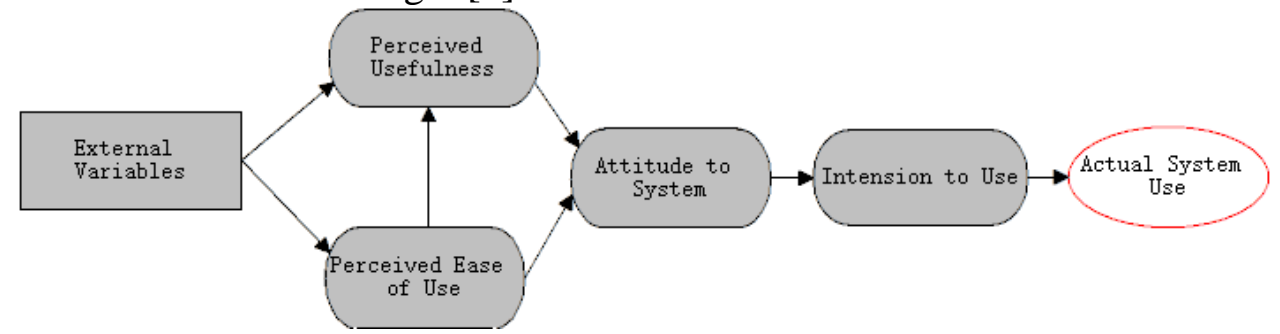

Fig.2 The Technology Acceptance Model (TAM)

\section{Methodology}

\subsection{Research model}

According to the relevant theoretical analysis and the actual need, the author put forward a initial teacher adoption model of mobile learning in teachers' educational technology ability training based on the TAM, as shown in figure Fig 3, and expanded the TAM. Two objective external factors were added to the objective part of the original model: Perceived Accessibility and Perceived Cost, two subjective external factors were added to the subjective part of the original model: Perceived Socialness and Perceived Enjoyment. 


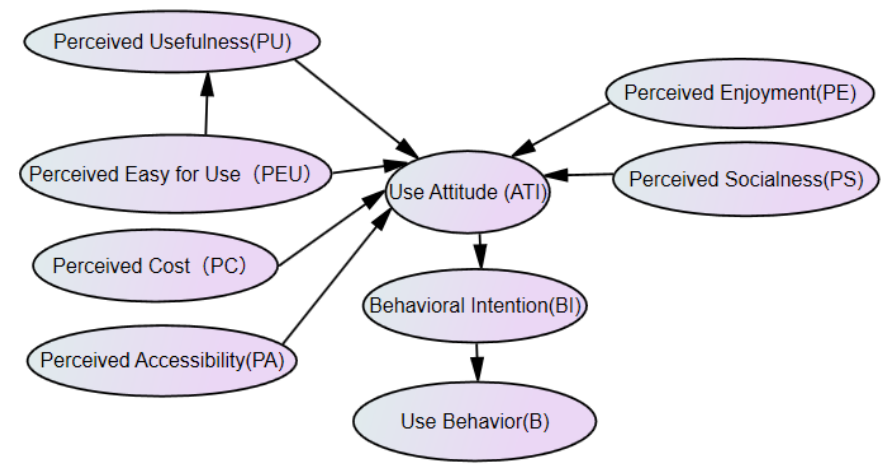

Fig.3 The initial model

\subsection{Research variables}

There were 9 variables included in the model. (1) Perceived Usefulness (PU), refer to only the users thinks that if things were useful to them or to the group, they will adopt the things. It's mainly explores how trainees perceive the usefulness of the mobile learning in Teachers' Educational Technology Ability Training including improve the teaching and learning, save time, the usefulness of the training resources and contents, promoting the renewal of ideas by mobile training. (2) Perceived Easy for Use (PEU) refers to the more the system ease for use, the more they like to use it. It's mainly explores how trainees perceive the mobile terminal of the training platform, the convenience of ease of use of the interfaces and operations.(3) Perceived Enjoyment(PE), mainly explores how students perceive the enjoyment about the mobile learning style, share the good resource and the pleasure of spiritual life.(4)Perceived Cost(PC), mainly explores how students perceive the cost of mobile learning, the device and network.(5) Perceived Socialness(PS) refers to the commonness of the group affects the behavior among the members of the community, the members incline to do the same thing in the community. It's mainly explores how the trainees perceive the colleagues' mobile learning behavior influencing their attitude toward mobile learning and their acceptance of the trend of online-training and mobile learning.(6)Perceived Accessibility(PA), mainly explores how the trainees perceive the accessibility of the learning platform with mobile terminal ,query the resources and the wireless network.(7)Use Attitude (ATI), mainly explores how the trainees perceive the sense of identity about the course and the attitude about use the mobile learning in their own teaching.(8) Behavioral Intention(BI), mainly explores how the trainees willing to accept the mobile training and share the learning resources with their colleagues and friends.(9)Use Behavior(B) , mainly explores whether the trainees can finish the course ,the frequency of use and the adopt the method and skills about mobile learning.

\subsection{Research hypothesis}

H1. The user's perceived usefulness about the mobile learning in educational technology ability training has a positive impact on the attitude of use.

H2. The user's perceived ease for use about the mobile learning in educational technology ability training has a positive impact on the attitude of use.

H3. The user's perceived enjoyment about the mobile learning in educational technology ability training has a positive impact on the attitude of use.

H4. The user's perceived socialness about the mobile learning in educational technology ability training has a positive impact on the attitude of use.

H5. The user's perceived accessibility about the mobile learning in educational technology ability training has a positive impact on the attitude of use.

H6. The user's perceived cost of the mobile learning in educational technology ability training has a positive impact on the attitude of use.

H7. The user's attitude of the mobile learning in educational technology ability training has a positive impact on the behavioral intention.

\subsection{Research Instrument}

The author designed a questionnaire based on the questionnaire "Investigation and research questionnaire of the mode of College Students' digital reading behavior based on TAM" designed 
by Zheng zhi-li in 2014[8] and "Questionnaire of the influencing factors of College Students' mobile learning" designed by Wu gang in 2014[9]. The items in the questionnaire used the Likert 5 level response model, scoring from "very consistent", "consistent", "general (difficult to determine)", "not consistent" to "very inconsistent", recorded as 5 to 1 points. And all items were adapted and refined from previous 2 studies to make them more specifically relevant to the current research. The questionnaire composed of student's background information and night factors mention above.

\subsection{Investigation procedure}

The author firstly selected 40 teachers in Guangdong Pharmaceutical University to make a pretest, and then improved the structure of the questionnaire according to the statistical internal consistency coefficient. The formal survey was conducted through the paper questionnaire and online survey from July to September in 2017.200 copies of the questionnaire were issued, and finally 161 questionnaires were received, 153 valid of them, and the effective recovery rate was $76.5 \%$. The valid questionnaires were coded with Microsoft Excel, and then imported into the SPSS 20, AMOS20 software for data analysis.

\subsection{Sample distribution}

The samples' professional title distribution was high professional title count for $28.1 \%$, middle professional title count for $64.1 \%$, primary professional title count for $7.8 \%$; The samples' teaching ages distribution was less than 4 Years count for 50.3\%, between 4 to 6 Years count for 26.1\%, more than 6 Years count for $23.5 \%$.

\section{Result}

\subsection{Questionnaire reliability}

The Reliability Statistics revealed that the internal consistency coefficient of questionnaire was high (Cronbach's Alpha= 0.961).The night variables’ Reliability were shown as Table1.

\subsection{The Structural Model}

As limited by the length of the article, the author did not further elaborate the process of model adjustment, and only showed the result of the final standardized teacher adoption model of mobile learning in teachers' educational technology ability training as Fig 4.

Table 1 Reliability test of variables

\begin{tabular}{|l|c|l|}
\hline Latent variables & Number of observed variables & Cronbach's Alpha \\
\hline Perceived Usefulness (PU) & 5 & 0.836 \\
\hline Perceived Easy for Use(PEU) & 4 & 0.735 \\
\hline Perceived Enjoyment (PE) & 3 & 0.795 \\
\hline Perceived Accessibility(PA) & 4 & 0.768 \\
\hline Perceived Cost(PC) & 3 & 0.782 \\
\hline Perceived Socialness(PS) & 3 & 0.744 \\
\hline Use Attitude (ATI) & 3 & 0.740 \\
\hline Behavioral Intention(BI) & 3 & 0.768 \\
\hline Use Behavior(B) & 4 & 0.846 \\
\hline
\end{tabular}




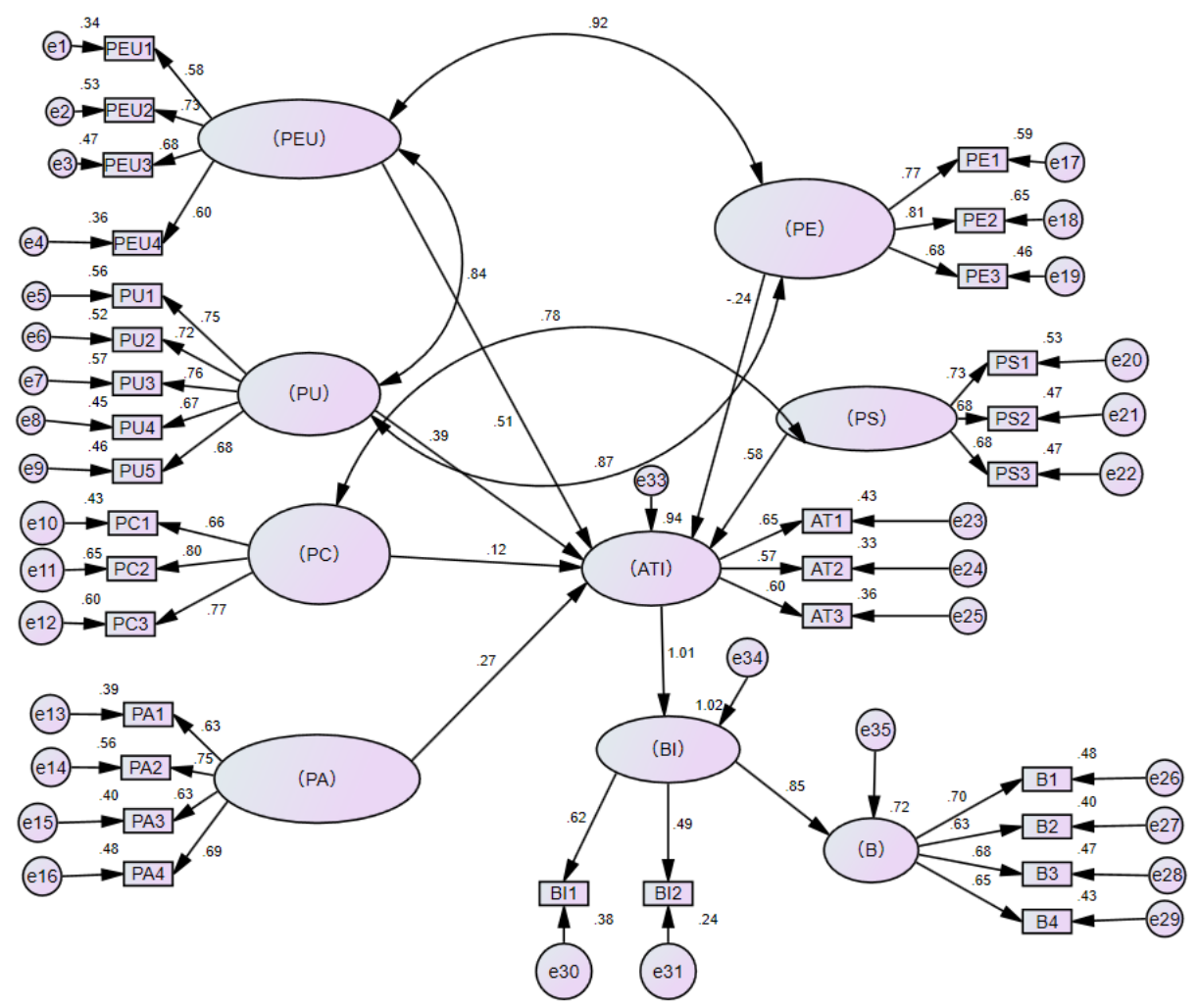

Fig.4 The standardized final model

\subsection{SEM Statistics of Model Fit}

The hypothesized structural equation model of teacher adoption of mobile learning in educational technology ability training was estimated using Maximum likelihood estimation with AMOS. It was found that the hypothesized model has shown an acceptable model fit, and the relevant parameters of the statistics are as follows: $X^{2}=1055.126$ with $\mathrm{df}=422, \mathrm{cmin} / \mathrm{df}=$ $2.50(<3.0)$, RMSEA $=0.09$, AGFI $=0.742(<0.8), \mathrm{GFI}=0.792(<0.9), p=0.00$.The author tried several adjust operations to improve the model, but it showed that the model was already the best in the current study. As the quantitative researches are inevitably directly affected by the limited amount of valid data, the existing models was acceptable. The relationship between the latent variables and the dependent variables can also effectively explain the logical relationship within the model obtained.

\subsection{Hypothesis testing results}

As the relationship shown in the standardized Final model, the result of hypothesis H1, H2, H4, H5, H6, H7 were supported. But the H3 Not Supported. Data analysis shows that, the factors include Perceived Usefulness ( PU ) , Perceived Easy for Use(PEU), Perceived Accessibility(PA),Perceived Cost(PC) , Perceived Socialness(PS) perceived usefulness about the mobile learning in educational technology ability training have a positive impact on the attitude of Use. The user's attitude of the mobile educational technology ability training has a positive impact on the behavioral intention. The Hypothesis testing results is shown as Table2. 
Table 2: Hypothesis testing results

\begin{tabular}{|l|l|l|l|}
\hline Hypotheses & Path & Hypothesis & Results \\
\hline H1 & PU $\rightarrow$ ATI & Positive & Supported \\
\hline H2 & PEU $\rightarrow$ ATI & Positive & Supported \\
\hline H3 & PE $\rightarrow$ ATI & Positive & Not Supported \\
\hline H4 & PS $\rightarrow$ ATI & Positive & Supported \\
\hline H5 & PA $\rightarrow$ ATI & Positive & Supported \\
\hline H6 & PC $\rightarrow$ ATI & Positive & Supported \\
\hline H7 & ATI $\rightarrow$ BIs & Positive & Supported \\
\hline
\end{tabular}

\subsection{Findings}

(1)There was a positive correlation between perceived usefulness and perceived ease of use in user mobile learning of training. It showed that if the learners feel the platform and resources are easy to use, they more likely to use them.(2) There was a positive correlation between perceived ease of use and perceived enjoyment in user mobile learning of training, indicating that learners feel the more easier use of learning platforms, and the more happy they feel about the learning.(3)There was a positive correlation between behavioral intention and behavior of use, indicating that possibility of completing training was closely relevant to the trainees' learning behavioral intention.

\section{Discussion and conclusions}

Perceived usefulness, perceived ease of use and perceived enjoyment were key factors to improve the quality of teachers' educational technology ability training. There were closely interrelations between the three factors. And the learners' attitude to the mobile learning in training directly related to learning intention.

It is most important to improve the teachers' sense of usefulness to the training of educational technology ability. According to the theory of adult learning, the trainees as adult learners have their characteristics, such as learn with definite target and selective about the content when they attend training. They like to learn new knowledge that has direct help and ease to pick up. To improve the usefulness of training, we should carefully analyze the students' learning needs, improve the system structure of the training content, attract learners with the latest and most useful knowledge, and provide examples of new teaching patterns to help them improve their teaching and study and provide some simple and useful teaching tool to promote their working efficiency.

Improving and using a powerful but easy to use training platform can make teachers feel ease of use in mobile learning. It is necessary to improve the human-computer interaction interface in the platform, and provide function practical and convenient for trainee to operate. For instance, in the Lanmoyun class platform, the system provided the mobile function including: sign in; keep track of students' attendance, the real time voting and the result analysis, etc. These functions enabled users learning with mobile devices, and it can help teachers put the way of mobile learning into their own teaching practice. Moreover, providing sufficient platform technical support for trainees can improve their proficiency in operation. The timely supports provided to help teacher to solute the technical problems can also improve their learning self-efficacy.

Some mechanisms should applied to improve the trainees' pleasure of the training, and develop system functions supporting them share the production and joys of learning in the course, encourage trainees to share their own learning experience. And pay attention to make the teaching resources (e.g. Micro lessons) more interesting, short and useful.

\section{Deficiency and limitation of the research}

As limited by the funds and manpower, the samples collected were relatively small, the final structural equation model obtained did not fully match the research hypothesis, but still acceptable. Some possible variables such as technical support, the self-efficiency, etc. may all be factors influence the mobile learning in teachers' educational technology ability training. These are what can be further explored in the follow-up study. 


\section{Acknowledgment}

This study was supported by the Cultivation Project for Excellent Young Teacher in Guangdong Universities (Grant \# YQ2015175 in 2015), Research Project of Educational Technology Reform in Higher Education Institutions of Guangdong Province (Grant \# 2015086 in 2015), Funded Project for research teams of Guangdong Teachers College of Foreign Language and Arts (Grant \# 2014KYTD01 in 2014). We want to thank all the participants in this study for their cooperation.

\section{References}

[1] Information on http://www.gov.cn/zhengce/content/2017-01/19/content_5161341.htm,2017-1-19.

[2] Information on http://www.moe.edu.cn/srcsite/A01/s7048/201007/t20100729_171904.html,2010-7-29.

[3] Information on http://down.qiexing.com/2011/11/et-gaoxiao.html,2011-11-29.

[4] Ma Ning, Chen Geng,et al. The Research of the National Educational Technology Guides for Teachers in Higher Education, Journal of Distance Education,29(2011)3-9.

[5] Information on http://www.mosoteach.cn,2017-1-22.

[6] Davis F. Perceived usefulness, perceived ease of use, and user acceptance of information technology[J]. MIS Quarte, 1989, 13(3): 319-341.

[7] Abbad, Morris, and de Nahlik, Looking under the Bonnet: Factors Affecting Student Adoption of E-Learning Systems in Jordan, International Review of Research in Open and Distance Learning.10 (2000) 1-23.

[8] Zheng zhi-li, Empirical Research on College Student's Digital Reading Behavior Based on the Technology Acceptance Model, Fudan University,Shanghai,China,2014

[9] Wu Gang, Research on Influence Factors of University Student's Willingness of Mobile Learning Base on TAM--A Case Study of Nanjing University of Posts and Telecommunications, Nanjing University of Posts and Telecommunications, Nanjing, China, 2014. 